\title{
Four-branched graft inversion technique for the distal anastomosis in acute aortic dissection
}

\author{
Yu Zou, Peng Teng and Liang Ma* (D)
}

\begin{abstract}
Background: Distal anastomosis bleeding is an issue during total arch replacement with the frozen elephant trunk technique. We used the 4-branched graft inversion technique for the distal anastomosis in acute aortic dissection. The aim was to evaluate the feasibility and benefits of the technique used during the frozen elephant trunk procedure for acute aortic dissection.

Methods: From January 2017 to July 2019, 109 patients underwent total arch replacement for type A acute aortic dissections. Patients were divided according to the technique used for the distal anastomosis as follows: group $G$ $(n=57$; 4-branched graft inversion technique) and group $C(n=52$; conventional method with Teflon felt). The postoperative variables were analysed.
\end{abstract}

Results: The hospital mortality rate was 9.2\% (10/109). The mean cardiopulmonary bypass, cardiac arrest, and circulatory arrest times were $234.95 \pm 71.88 \mathrm{~min}, 168.25 \pm 61.33 \mathrm{~min}$, and $39.19 \pm 9.45 \mathrm{~min}$, respectively. The circulatory arrest and cardiac arrest times were shorter in the graft inversion group than in the conventional group $(36.46 \pm 7.88 \mathrm{~min}$ vs. $42.19 \pm 10.17 \mathrm{~min}, P=0.001$ and $156.21 \pm 55.99 \mathrm{~min}$ vs. $181.44 \pm 64.68 \mathrm{~min}, P=0.031$, respectively). There were 7 cases of stroke (6.4\%) and 5 cases of paraplegia (4.6\%). Additionally, 13 patients (11.9\%) required temporary continuous renal replacement therapy. Respiratory failure occurred in 19 patients (17.4\%). There were no significant differences in postoperative complications between the two groups.

Conclusions: The 4-branched graft inversion technique provides effective and confirmed haemostasis during total aortic arch replacement using the frozen elephant trunk procedure.

Keywords: Aortic arch, Aortic dissection, Bleeding, Frozen elephant trunk, Distal anastomosis

\section{Background}

Acute type A aortic dissection is a surgical emergency with a high mortality rate [1]. The prognosis of total aortic replacement for acute type A aortic dissection is unsatisfactory [2], and bleeding is one of the main reasons. Owing to limited surgical exposure and poor aortic texture, distal anastomosis bleeding is sometimes an issue
[3]. At present, several techniques have been reported [1, 4-7]. The branched graft inversion technique developed by Tanaka et al. [8]. However, this technique has been only applied to elective thoracic aortic aneurysms. In this paper, we report the first application of this technique in total aortic arch replacement using the frozen elephant trunk (FET) technique for the treatment of acute type A aortic dissection and summarise our experience.

*Correspondence: ml1402@zju.edu.cn

Department of Cardiovascular Surgery, The First Affiliated Hospital of Medical College, Zhejiang University, 79 Qing Chun road, Hang

Zhou 310003, Zhejiang Province, China original author(s) and the source, provide a link to the Creative Commons licence, and indicate if changes were made. The images or other third party material in this article are included in the article's Creative Commons licence, unless indicated otherwise in a credit line to the material. If material is not included in the article's Creative Commons licence and your intended use is not permitted by statutory regulation or exceeds the permitted use, you will need to obtain permission directly from the copyright holder. To view a copy of this licence, visit http://creativecommons.org/licenses/by/4.0/. The Creative Commons Public Domain Dedication waiver (http://creativecommons.org/publicdomain/zero/1.0/) applies to the data made available in this article, unless otherwise stated in a credit line to the data. 


\section{Patients and methods Patients}

Between January 2017 and July 2019, 109 patients (91 males) at our centre underwent total arch replacement using the FET technique for type A acute aortic dissection. The mean patient age was $47.10 \pm 11.16$ years. Diagnoses were confirmed by computed tomography angiography (CTA), and all patients underwent emergency surgery. The characteristics of the patients are shown in Table 1. The 4-branched graft inversion technique was applied to distal anastomosis in 57 cases (group G). Conventional end-to-end anastomosis was used in 52 cases (group C).

All strokes were confirmed by computed tomography. Postoperative renal insufficiency was defined by the requirement for continuous renal replacement therapy. Respiratory failure was defined as more than $72 \mathrm{~h}$ of postoperative mechanical ventilation.

\section{Surgical technique}

All patients underwent median sternotomy in the supine position. The right axillary artery was exposed, and an arterial cannula was inserted for cardiopulmonary bypass (CPB) and selective cerebral perfusion (SCP). A cavoatrial cannula was inserted into the right atrium. Left ventricular venting was performed through the right superior pulmonary vein. Cardiac arrest was achieved as usual. Before deep hypothermia occurred, the Bentall or aortic valve replacement procedure was performed if aortic valve lesions were present. The stepwise technique as described by Inoue et al. [9] was applied to the proximal anastomosis for patients without aortic valve lesions. Bentall, David, or aortic valve replacement was performed for patients with aortic valve lesions. Once the rectal temperature was reduced to $20{ }^{\circ} \mathrm{C}$, deep hypothermic circulatory arrest began. The usual procedure was performed. After the proximal end of the left

Table 1 Patient characteristics

\begin{tabular}{lllll}
\hline & $\begin{array}{l}\text { Total } \\
\text { (n=109) }\end{array}$ & $\begin{array}{l}\text { Group G } \\
\text { (graft } \\
\text { inversion) } \\
(\mathbf{n}=\mathbf{5 7})\end{array}$ & $\begin{array}{l}\text { Group C } \\
\text { (conventional) } \\
(\mathbf{n}=\mathbf{5 2})\end{array}$ & $\begin{array}{l}\boldsymbol{P} \\
\text { value }\end{array}$ \\
\hline Mean age & $47.10 \pm 11.16$ & $46.35 \pm 12.60$ & $47.92 \pm 9.39$ & 0.465 \\
Male/female & $91 / 18$ & $49 / 8$ & $42 / 10$ & 0.466 \\
Organ malperfusion & & & \\
Cerebral & $3(2.8 \%)$ & $2(3.5 \%)$ & $1(1.9 \%)$ & 0.613 \\
Coronary & $6(5.5 \%)$ & $2(3.5 \%)$ & $4(7.7 \%)$ & 0.339 \\
Kidney & $7(6.4 \%)$ & $3(5.3 \%)$ & $4(7.7 \%)$ & 0.605 \\
Spinal cord & 0 & 0 & 0 & \\
Leg & $8(7.3 \%)$ & $5(8.8 \%)$ & $3(5.8 \%)$ & 0.548 \\
\hline
\end{tabular}

subclavian artery was closed by a $5-0$ running suture, a frozen elephant stent (Cronus; Microport Medical Co., Ltd., Shanghai, China), which comprises two parts: a $20 \mathrm{~mm}$ stent-free vascular graft at the proximal end and a $100 \mathrm{~mm}$ self-expandable stent graft at the distal end, was inserted into the true lumen of the descending aorta (Fig. 2a).The proximal part of the stent(stent-free graft) is used to anastomose with the quadrifurcated prosthetic graft. The distal part(self-expandable stent graft) can support dissected descending aorta. In the conventional group, the distal end of a quadrifurcated prosthetic graft (Hemashield Platinum; Intervascular SAS, La Ciatot, France) was directly end-to-end anastomosed to the proximal end of the descending aorta and the frozen stent inside with Teflon felt. In group G, a 4-branched prosthetic graft was trimmed to the appropriate length (Fig. 1a) and inverted completely (Fig. 1b, c). The distal end of the graft, the 4 branches, and the proximal end of the graft are cut to about $1 \mathrm{~cm}, 3 \mathrm{~cm}$, and $4 \mathrm{~cm}$, respectively (Fig. 1a). Thereafter, the invaginated graft was carefully inserted into the stent graft. The openings of the three branches always faced the greater curvature of the aortic arch (Fig. 2b), which ensures the three branches are at the correct position when the graft is pulled out. The ends of the quadrifurcated graft, elephant stent, and native aortic wall were trimmed to the same level and sewed together with a Teflon felt strip using a 4-0 Prolene running suture (Fig. 3a). Finally, the 4-branched inverted graft was gently pulled out with forceps (Fig. 3b). In both groups $\mathrm{G}$ and $\mathrm{C}$, antegrade circulatory perfusion resumed through the fourth branch of the graft. The left subclavian artery, left common carotid artery, and innominate artery were reconstructed in the order written. The 4-branched graft was anastomosed to the proximal graft at the end of the procedure (Fig. 4a).

\section{Statistical analysis}

Data were analysed using SPSS 19 software (IBM Corp., Armonk, NY, USA) for Windows. Continuous variables are reported as means \pm standard deviations (SDs). Categoric data are described as frequencies and percentages. The independent samples $t$ test or chi-square test was used for comparison.

\section{Results}

A total of 109 patients underwent ascending aorta replacement, total arch replacement, and FET implantation. The following concomitant procedures were performed: coronary artery bypass grafting (CABG) (6 patients), aortic valve replacement (3 patients), Bentall (28 patients), tricuspid valve plasty (3 patients), and subvalvular aortic stenosis resection (1 patient). The mean $\mathrm{CPB}$, cardiac arrest, and circulatory arrest 

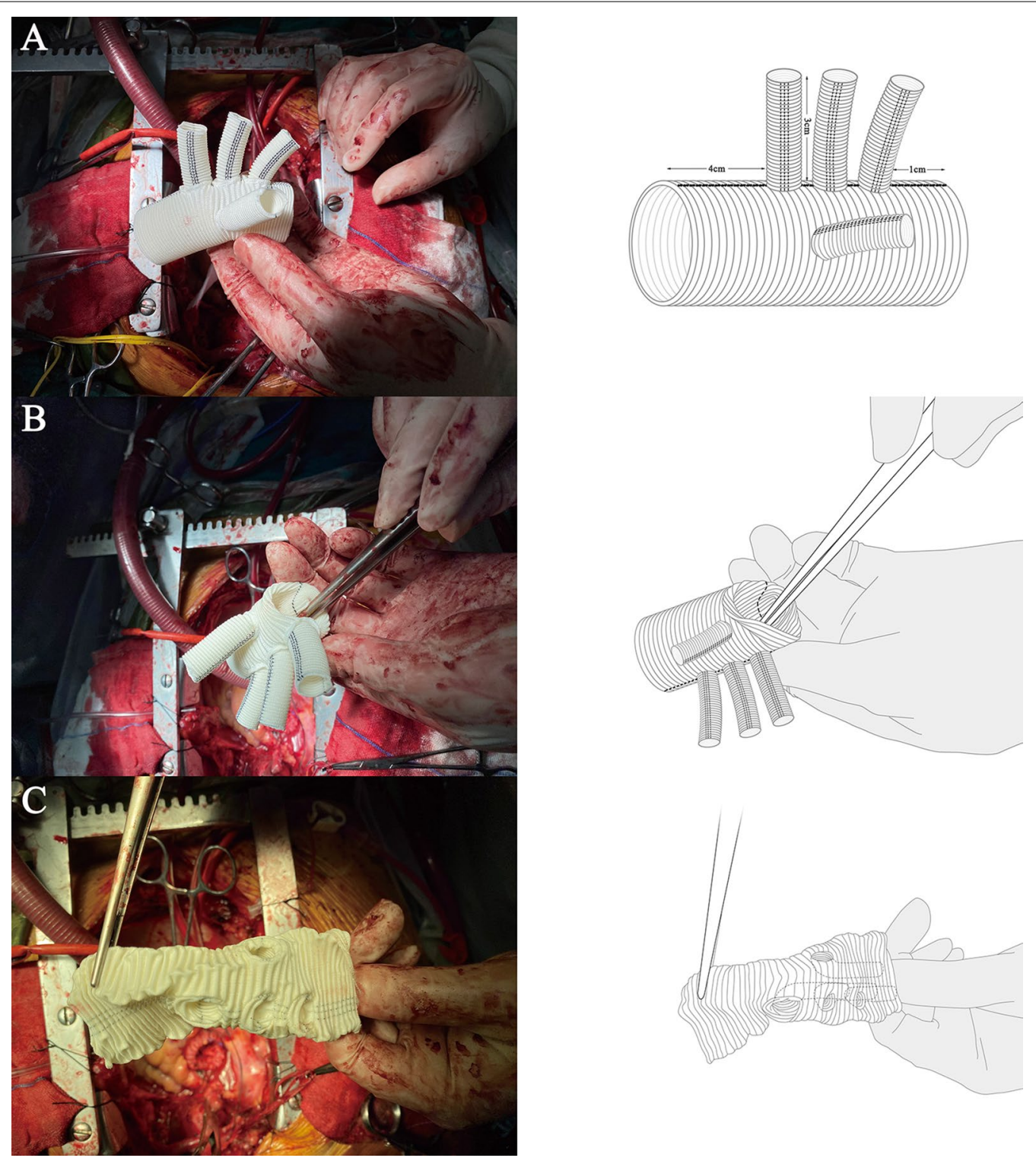

Fig. 1 A 4-branched graft was inverted in the operation. a A 4-branched prosthetic graft was trimmed to the appropriate length. $\mathbf{b}$ The trimmed graft was inverted with forceps. c The completely inverted 4-branched graft

times were $234.95 \pm 71.88 \mathrm{~min}, 168.25 \pm 61.33 \mathrm{~min}$, and $39.19 \pm 9.45 \mathrm{~min}$, respectively. The mean operative time was $366.18 \pm 68.70 \mathrm{~min}$. The circulatory arrest and cardiac arrest times were shorter in group $G$ than in the conventional group (36.46 $\pm 7.88 \mathrm{~min}$ vs. $42.19 \pm 10.17 \mathrm{~min}$, $P=0.001$ and $156.21 \pm 55.99$ vs. $181.44 \pm 64.68, P=0.031$, respectively). No significant differences in cardiopulmonary bypass and operative times were observed between the two groups.

The hospital mortality rate was $9.2 \%$ (10/109; group G, 4/57 [7.0\%]; group C, 6/52 [11.5\%]). The causes of death included right heart failure $(n=2)$, stroke $(n=1)$, multiple organic failure $(n=2)$, sudden ventricular arrhythmia $(\mathrm{n}=1)$, sepsis due to pulmonary infection $(\mathrm{n}=2)$, and ischaemic organ necrosis $(\mathrm{n}=2)$. Three patients (all in group C, 3/52 [5.8\%]) were rechecked for bleeding. There were 7 strokes (3 [5.3\%] in group G and 4 [7.7\%] in group C). Additionally, 5 patients (4.6\%) had paraplegia, and 4 of them recovered after treatment. Moreover, 13 patients (11.9\%) required temporary continuous renal replacement therapy, and 2 patients developed the need for chronic dialysis. Respiratory failure occurred in 19 patients. Other postoperative data are shown in Table 2. 

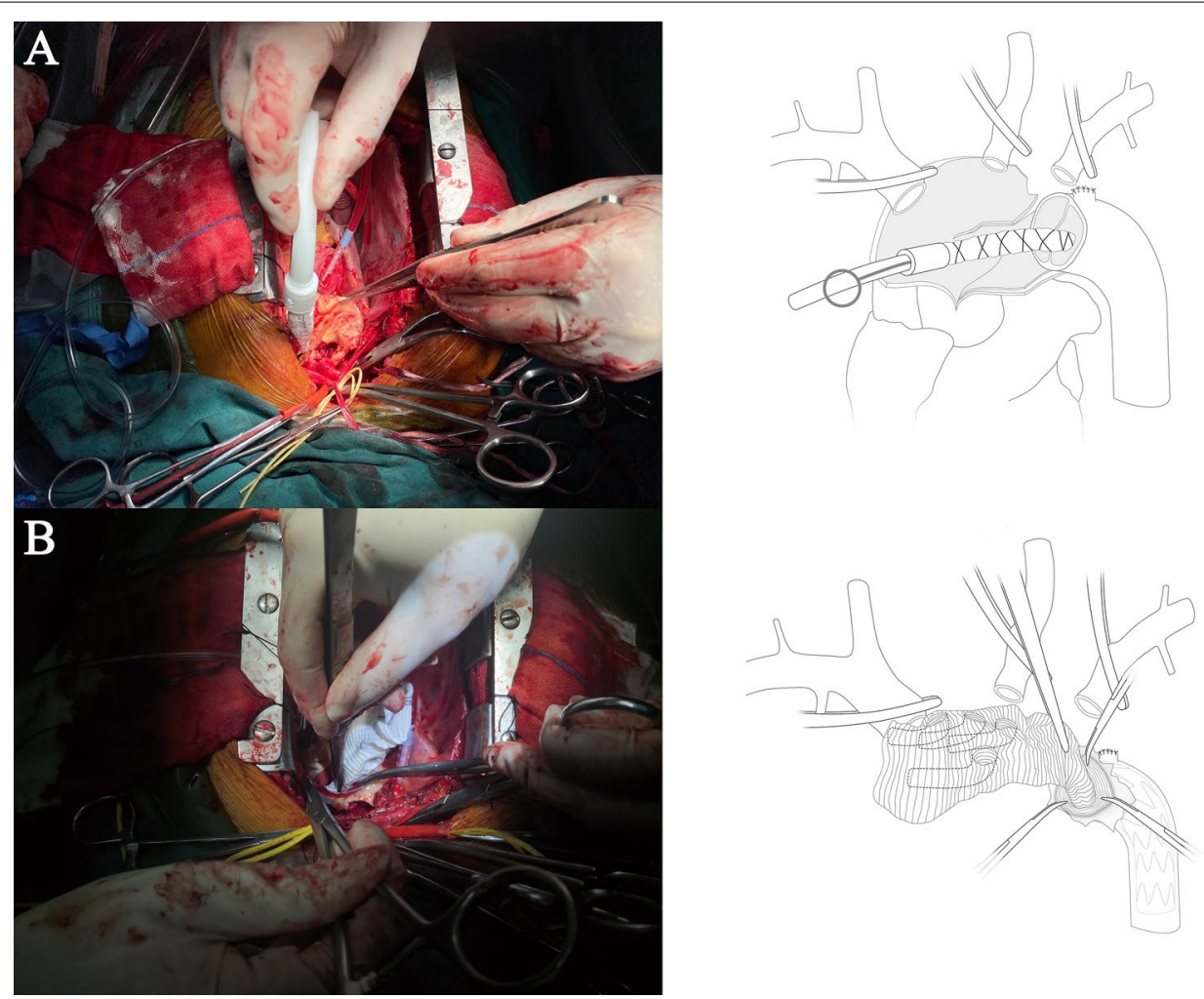

Fig. 2 a A frozen elephant stent was inserted into the true lumen of the descending aorta. $\mathbf{b}$ The invaginated graft was carefully inserted into the stent graft. The openings of the 3 branches always faced the greater curvature of the aortic arch

\section{Discussion}

The FET technique is an effective approach with good long-term results for chronic or acute aortic dissection involving the arch [10-12]. In conventional distal anastomosis, the quadrifurcated prosthetic graft does not fit well with the stent graft and the native aortic wall [7]. However, the anastomosis is relatively quick owing to the limited circulation arrest time. Bleeding at the distal anastomosis is a tricky problem. The reverse stepwise technique is a good method [13], but it involves the connection of a graft between the 4-branched graft and frozen stent, which increases the risk of bleeding at the graft-to-graft anastomosis. Most importantly, the hypothermic circulatory time increases [1]. The branched graft inversion technique was first developed by Tanaka et al. It is used for aortic arch replacement in elective surgery for thoracic aortic aneurysms without the frozen elephant stent procedure. Tanaka also mentioned the limitation of this technique: it is not suitable for acute aortic dissection because of the presence of dissection, which can cause an intima tear [8]. We first applied the 4-branched graft inversion technique during the FET procedure for the treatment of acute type A aortic dissection. During the process of prosthetic graft insertion, the aortic intima is isolated and unwounded because of the frozen stent in the descending aorta. The deep hypothermic circulatory arrest and cardiac arrest times are greatly reduced using this technique. In 57 patients, uncontrolled distal anastomotic bleeding did not occur, and statistical analysis indicated that the rates of postoperative stroke, other complications, and mortality were the same as those who had undergone the traditional anastomosis method.

This method has several advantages. First, the quadrifurcated prosthetic graft is directly anastomosed with the frozen stent, which decreases the hypothermic circulatory arrest time. Second, the quadrifurcated prosthetic graft fits to the stent graft and native aortic wall well, speeding up the anastomosis. Third, uncontrollable bleeding almost never occurs. Fourth, a good surgical view allows rapid anastomosis without interruption by the 4-branched graft.

When using this method, it is also necessary to pay attention to various factors. First, the 4-branched prosthetic graft must be trimmed to the appropriate length. In our centre, we cut it as short as possible based on the premise that this will guarantee anastomosis. The distal end of the graft, the 4 branches, and the proximal end of the graft are cut to about $1 \mathrm{~cm}, 3 \mathrm{~cm}$, and $4 \mathrm{~cm}$, 

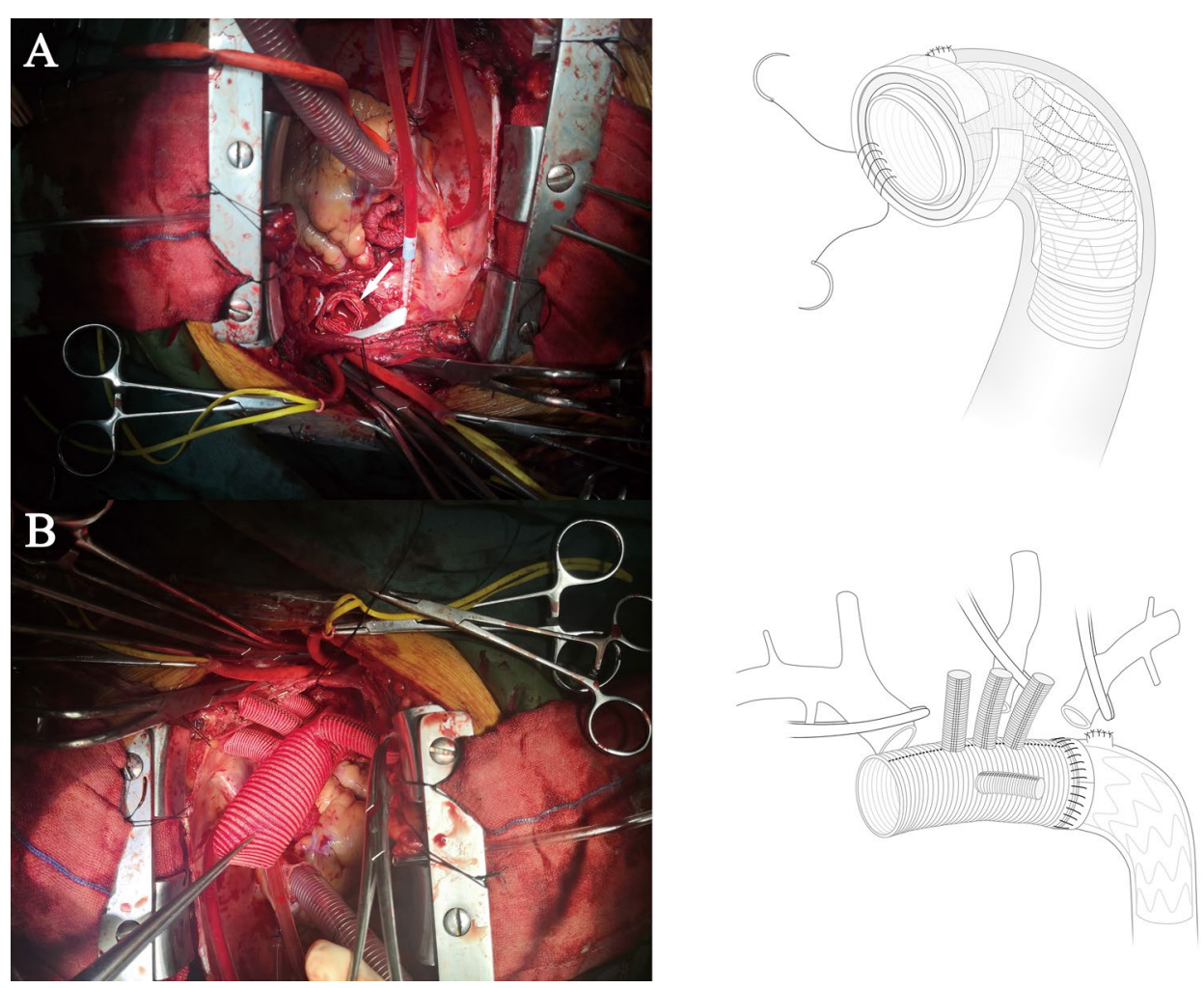

Fig. 3 a The ends of the quadrifurcated graft, elephant stent, and native aortic wall were trimmed to the same level and sewn together with a Teflon felt strip using a 4-0 Prolene running suture (white arrow). b The 4-branched inverted graft was pulled out with forceps

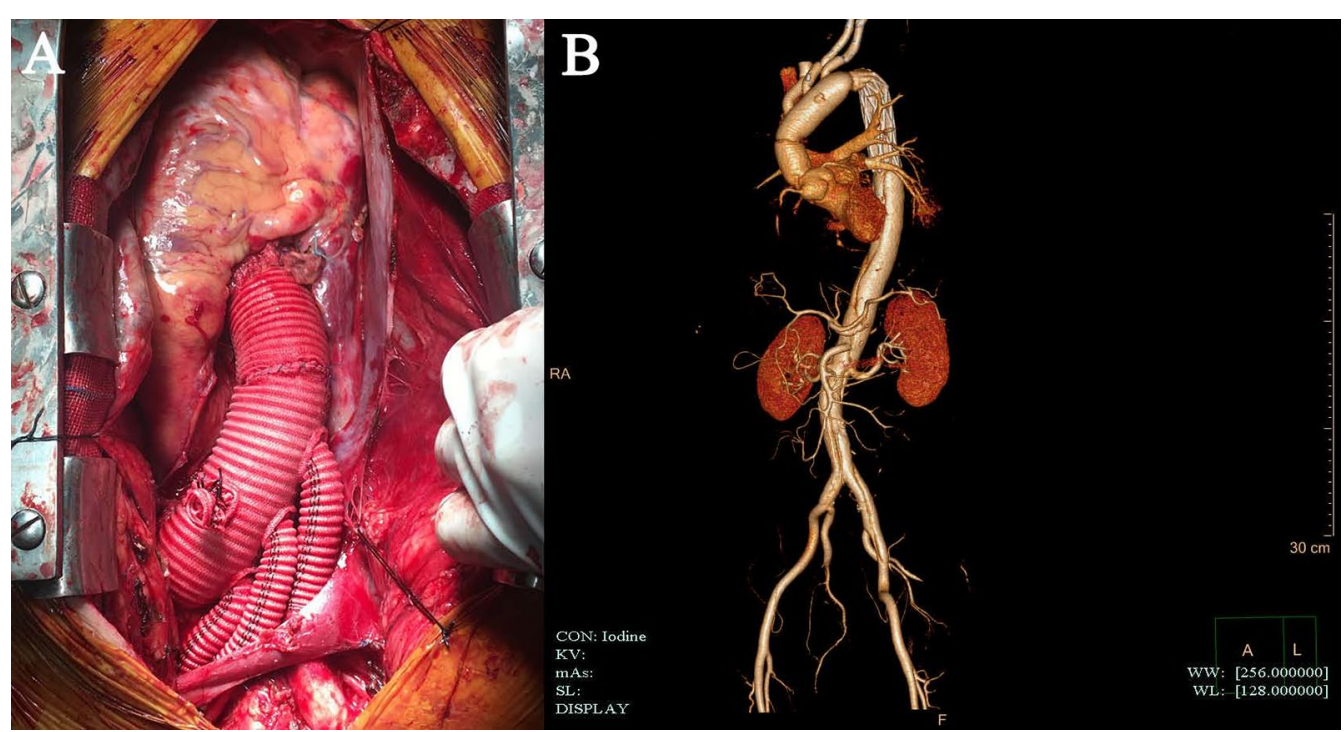

Fig. 4 a Final aspect of the surgery. $\mathbf{b}$ Postoperative 3-dimensional computed tomography of the aorta

respectively. Second, during the insertion process, the openings of the 3 branches should always face the greater curvature of the aortic arch.

\section{Conclusions}

For total aortic arch replacement with the FET procedure, the 4-branched graft inversion technique involves 
Table 2 Operative variables and early postoperative complications

\begin{tabular}{|c|c|c|c|c|}
\hline & $\begin{array}{l}\text { Total } \\
(n=109)\end{array}$ & $\begin{array}{l}\text { Group G } \\
\text { (graft inversion) } \\
(\mathrm{n}=57)\end{array}$ & $\begin{array}{l}\text { Group C } \\
\text { (conventional) } \\
(n=52)\end{array}$ & $P$ value \\
\hline HCA time & $39.19 \pm 9.45$ & $36.46 \pm 7.88$ & $42.19 \pm 10.17$ & 0.001 \\
\hline CA time & $168.25 \pm 61.33$ & $156.21 \pm 55.99$ & $181.44 \pm 64.68$ & 0.031 \\
\hline CPB time & $234.95 \pm 71.88$ & $231.35 \pm 72.85$ & $238.90 \pm 71.30$ & 0.586 \\
\hline Operation time & $366.18 \pm 68.70$ & $355.70 \pm 70.053$ & $377.67 \pm 65.94$ & 0.096 \\
\hline \multicolumn{5}{|l|}{ Concomitant procedure } \\
\hline CABG & $6(5.5 \%)$ & $2(3.5 \%)$ & $4(7.7 \%)$ & 0.339 \\
\hline AVR & $3(2.8 \%)$ & $1(1.8 \%)$ & $2(3.8 \%)$ & 0.505 \\
\hline Bentall & $28(25.7 \%)$ & $13(22.8 \%)$ & $15(28.8 \%)$ & 0.471 \\
\hline TVP & $3(2.8 \%)$ & $2(3.5 \%)$ & $1(1.9 \%)$ & 0.613 \\
\hline SAS & $1(0.9 \%)$ & 0 & $1(1.9 \%)$ & 0.293 \\
\hline Re-exploration for bleeding & $3(2.8 \%)$ & 0 & $3(5.8 \%)$ & 0.066 \\
\hline Hospital mortality & $10(9.2 \%)$ & $4(7.0 \%)$ & $6(11.5 \%)$ & 0.414 \\
\hline \multicolumn{5}{|l|}{ Major complications } \\
\hline Stroke & $7(6.4 \%)$ & $3(5.3 \%)$ & $4(7.7 \%)$ & 0.605 \\
\hline Paraplegia & $5(4.6 \%)$ & $2(3.5 \%)$ & $3(5.8 \%)$ & 0.573 \\
\hline Heart failure & $6(5.5 \%)$ & $3(5.3 \%)$ & $3(5.8 \%)$ & 0.908 \\
\hline Respiratory failure & $19(17.4 \%)$ & $11(19.3 \%)$ & $8(15.4 \%)$ & 0.591 \\
\hline Renal insufficiency (CRRT) & $13(11.9 \%)$ & $5(14.0 \%)$ & $8(9.6 \%)$ & 0.287 \\
\hline
\end{tabular}

$H C A$ hypothermic circulatory arrest, $C A$ cardiac arrest, $C P B$ cardiopulmonary bypass, $C A B G$ coronary artery bypass grafting, $A V R$ aortic valve replacement, TVP tricuspid valve plasty, SAS subvalvular aortic stenosis, CRRT continuous renal replacement therapy

simple and fast distal anastomosis for acute type A aortic dissection. It provides effective and confirmed haemostasis and reduces the circulatory arrest time.

\section{Abbreviations}

FET: Frozen elephant trunk; CPB: Cardiopulmonary bypass; CTA: Computed tomography angiography; SCP: Selective cerebral perfusion; CABG: Coronary artery bypass grafting.

\section{Acknowledgements \\ Not applicable.}

\section{Authors' contributions}

(I) Conception and design: LM; (II) Administrative support: LM, YZ; (III) Provision of study materials or patients: $Y Z$; (IV) Collection and assembly of data: $Y Z$; (V) Data analysis and interpretation: All authors; (VI) Manuscript writing: All authors; (VII) All authors read and approved the final manuscript.

\section{Funding}

Zhejiang Province Public Welfare Technology Application Research Project (LGF19H020012)

\section{Availability of data and materials}

Please contact author for data requests.

\section{Declarations}

Ethics approval and consent to participate Not applicable.

\section{Consent for publication}

Not applicable.
Competing interests

The authors declare that they have no competing interests.

Received: 7 December 2020 Accepted: 19 September 2021

Published online: 30 October 2021

\section{References}

1. Matsuyama S, Tabata M, Shimokawa T, Matsushita A, Fukui T, Takanashi S. Outcomes of total arch replacement with stepwise distal anastomosis technique and modified perfusion strategy. J Thorac Cardiovasc Surg. 2012;143(6):1377-81.

2. Oda T, Minatoya K, Sasaki H, et al. Adventitial inversion technique for type a aortic dissection distal anastomosis. J Thorac Cardiovasc Surg. 2016;151(5):1340-5.

3. Ogino $\mathrm{H}$. Open repair of distal aortic arch and proximal descending thoracic aortic aneurysm using a stepwise distal anastomosis. Oper Tech Thorac Cardiovasc Surg. 2007;12(3):162-6.

4. David TE. Adventitial inversion in the distal anastomosis in surgical treatment of acute Debakey type A aortic dissection. J Thorac Cardiovasc Surg. 2016;151(5):1346-7.

5. Kim JH, Na CY. A simplified inversion technique for the frozen elephant trunk procedure using a four-branched graft. Thorac Cardiovasc Surg. 2013;61(7):587-9.

6. Liu K, Zhu C, Zheng X, et al. A new aortic arch inclusion technique with frozen elephant trunk for type an aortic dissection. Ann Surg. 2020;271(5):978-83.

7. Sako H, Tanaka H, Morita M, Takayama T. Devising a technique for distal anastomosis during total arch replacement using the frozen elephant trunk technique: reverse stepwise anastomosis. Gen Thorac Cardiovasc Surg. 2018;66(8):492-4 
8. Tanaka K, Yoshitaka H, Irie Y, et al. Branched graft inversion technique for distal anastomosis in total arch replacement. Ann Thorac Surg. 2012;94(3):1015-7.

9. Inoue Y, Minatoya K, Itonaga T, et al. Utility of proximal stepwise technique for acute aortic dissection involving the aortic root. Ann Thorac Surg. 2016;101(5):e183-185.

10. Kato M, Ohnishi K, Kaneko M, Ueda T, Matsuda H. New graft-implanting method for thoracic aneurysm or dissection with a stented graft. Circulation 1996;94(9 Suppl):II188-193.

11. Kokotsakis J, Anagnostakou V, Kratimenos T, Ashrafian H, Athanasiou T. Frozen elephant trunk: a technique which can be offered in complex pathology to fix the whole aorta in one setting. J Cardiothorac Surg. 2011:6(1):66.
12. Uchida N, Katayama A, Higashiue S, et al. A new device as an open stent graft for extended aortic repair: a multicentre early experience in Japan. Eur J Cardiothorac Surg. 2016;49(4):1270-8.

13. Ogino H, Ando M, Sasaki H, Minatoya K. Total arch replacement using a stepwise distal anastomosis for arch aneurysms with distal extension. Eur J Cardiothorac Surg. 2006;29(2):255-7.

\section{Publisher's Note}

Springer Nature remains neutral with regard to jurisdictional claims in published maps and institutional affiliations.
Ready to submit your research? Choose BMC and benefit from:

- fast, convenient online submission

- thorough peer review by experienced researchers in your field

- rapid publication on acceptance

- support for research data, including large and complex data types

- gold Open Access which fosters wider collaboration and increased citations

- maximum visibility for your research: over $100 \mathrm{M}$ website views per year

At BMC, research is always in progress.

Learn more biomedcentral.com/submissions 